\title{
Bidder Experience In Online Auctions: Effects On Bidding Choices And Revenue
}

Sidne G. Ward, (E-mail: wards@umkc.edu), University of Missouri - Kansas City John M. Clark, (E-mail: clarkjm@umkc.edu), University of Missouri - Kansas City

\begin{abstract}
This paper describes research to determine the effects of bidder experience on performance in online auctions. Choice of bid type, the timing of bids, and the price paid are all examined for very experienced and very inexperienced bidders. The study draws on information systems empirical research, traditional auction theory, the results of lab experiments involving "live" auctions not mediated by computers, and existing research on online auctions. The results indicate that bidder experience is related to timing of bids and choice of bid type, but not to revenue realized. These findings have implications for bidders and researchers.
\end{abstract}

\section{Introduction}

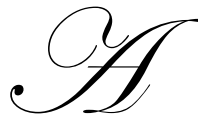

number of online auction sites have sprung up on the web over the last few years selling everything from collectibles to computer hardware and software. Lucking-Reiley (2000) identified 142 different sites in a survey of online auction web sites in 1998. One such site, eBay, had more than 49 million registered users as well as 145 million auctions during the second quarter of 2002 (eBay, 2002). As this new device for facilitating auctions has become widespread, applying the results of existing information systems and auction research including traditional auction theory to an examination of bidder behavior may provide valuable lessons bidders and auction researchers. This study examines single-item auctions on a particular online auction site, eBay, to determine whether predictions based on traditional auction theory as well as laboratory experiments on auctions and on the use of information systems hold true.

\section{Information Systems And Experience}

Previous research in the information systems literature on user experience and software indicates that users with more experience perform more highly than users with less experience. Examples include Alavi and Joachimsthaler's (1992) meta-analysis of decision support systems implementation research that found user experience with those systems had a positive effect on performance. Bidders who are more experienced with eBay bidding processes and formats may similarly perform better than those with less experience.

\section{Traditional Auction Theory And Experimental Results}

This study examines auction theory related to English and first-price and second-price sealed bid auctions. The most common type of auction is the English auction. English auctions start the bidding and increase the price until only one bidder remains. Participants in the auction know who the bidders are and what the current high bid is during the auction. The highest bidder then pays the price he or she bid for the auctioned item. Both first-price and second-price sealed bid auctions entail soliciting sealed bids and declaring the highest bidder the winner. In the case of the second-price sealed bid the highest bidder is required to pay the amount of the second highest bid for the auctioned item.

Readers with comments or questions are encouraged to contact the authors via email. 
Values are independent when bidders have no information concerning other bidders' values for the item. If it is the case that when bidders receive information indicating their values for an item are likely to be high (or low) this indicates that other bidders' values are also likely to be high (or low) values are affiliated. An additional distinction is made between private and common values. Values are private when the auctioned item has a different value for each bidder, as is the case with collectibles. Auctioned items exhibit common values when they hold the same value for all bidders, as is the case with mineral rights.

Vickrey (1961) demonstrates that English auctions, first-price sealed bid auctions, and second-price sealed bid auctions should result in the same revenue to the seller when values for the auctioned item are independent and private. Milgrom and Weber's (1982) general theoretical model demonstrates that in an affiliated private value context, when bidders know how much they value the item, that revenue realized by English and second-price sealed bid auctions should be equivalent as well as higher than bids in first-price sealed bid auctions.

Many laboratory experiments have been conducted to test these theoretical premises. Several examine bidder experience as a factor influencing how closely the studied auctions conform to theory. Results of laboratory experiments on both common and private value auctions by Coppinger, Smith, and Titus (1980), Kagel and Levin (1986), Kagel et al. (1989), Garvin and Kagel (1994), Levin, Kagel, and Richard (1996), Avery and Kagel (1997), and List and Shogren (1999) indicate that inexperienced bidders perform more poorly than those more experienced. Bidders with little practice bid further away from the theoretical optimal level than more practiced bidders. Although the preponderance of the evidence supports this view, Kagel, Harstad, and Levin (1987) and Dyer, Kagel, and Levin (1989) indicate that experienced bidders do not perform better under all circumstances. In particular, the Kagel, Harstad, and Levin (1987) study examined bidders in second-price sealed bid auctions and concluded their performance did not improve significantly over the course of 30 or 31 auctions. The lack of increase in performance was attributed to the deficient information bidders receive in auctions utilizing this mechanism.

\section{Information Systems And Auctions}

Information systems researchers have recently commenced examinations of online auctions. Pavlou and Ba (2000) discovered a positive relationship between seller feedback on eBay and revenue realized in auctions. Their study examines seller feedback as an indication of reputation and trustworthiness, yet the increase in performance, i.e., greater revenue, may partially be due to the experience of the seller in placing the auction. Bidders with more experience may find their performance similarly increases.

Vakrat and Seidmann (1999) assert that bidders prefer short auctions to avoid delays, the need to search for another auction in the event of unsuccessful bidding, and the effort of monitoring the auction to update bids if necessary. More experienced bidders may be more likely to realize the advantages of auctions ending sooner relative to auctions with later ending times and to seek out auction features which reduce monitoring costs.

Ward and Clark (2002) found no significant relationship between bidder experience on eBay and revenue realized in auctions. Nevertheless, that study examined bidders from an entire range of experience, comparing very experienced bidder performance to very inexperienced bidder performance may obtain different results.

\section{5. eBay Characteristics}

We chose to focus on a particular site, eBay. Lucking-Reiley (2000) found that eBay auctions brought in more than 10 times the revenue of its closest competitor. Indeed, gross merchandise sales for the second quarter of 2002 were $\$ 3.4$ billion (eBay, 2002). An analysis of eBay auctions should yield data sufficient to draw well-supported conclusions regarding the effects of bidder experience.

In the collectibles section of eBay most auctions entail sellers offering a single item for sale and setting a minimum bid for the item. If an auction attracts at least one bid, the seller and the highest bidder are obligated to conclude the transaction. Sellers may set reserve prices higher than the minimum bid and hidden from bidders. The auction description includes the information that the item has a reserve price and whether or not that reserve price has 
been met. If at least one bid equal to or higher than the reserve price is submitted, the seller and highest bidder are obligated to conclude the transaction.

Sellers on eBay may choose to run auctions for three, five, seven, or ten days. Auctions close exactly at the time of day as originally posted. For example, if a seller begins a three day auction at 11:15:34 a.m. on October 3, the auction closes at 11:15:34 a.m. on October 6.

Bids on eBay must exceed the current high bid by at least a minimum increment as set by eBay. For example, if an auction has a current high bid of $\$ 15.00$, the next bidder must submit a bid of at least $\$ 15.50$. In addition to minimum bid increment, English-style, bids, eBay has a feature which allows a bidder to enter the maximum amount he or she is willing to pay for an item. The system automatically executes bids based on the current highest bid plus the minimum bid increment. eBay uses the term "proxy" bidding to describe this type of bid.

Bids submitted early in the auction process take precedence over bids submitted later in the auction in the case of ties. For example, an eBay bidder submits a proxy bid with a maximum level of $\$ 20.00$ early in the auction, the next highest bid is $\$ 15.00$, so the early proxy bidder is listed as the current high bidder at $\$ 15.50$. In the last few minutes of the auction a different bidder submits another proxy bid for $\$ 20.00$. The bid submitted earlier is declared the winning bid.

Finally, eBay provides data that may be used to estimate the experience of both sellers and bidders. After an auction ends and the transaction is concluded, both the seller and the winning bidder have the opportunity to leave a feedback rating for the other party. The feedback consists of a short, verbal description of the transaction and a rating of "positive," "negative," or "neutral." Each positive remark from a unique eBay user adds one point to a users' overall feedback rating while a negative remark leads to the subtraction of a point. Neutral remarks do not affect the overall rating. Most eBay users have many more positive than negative points. These ratings are often used as a proxy for the experience of the participants (Pavlou and Ba, 2000).

\section{6. eBay Versus Traditional Auctions}

Auctions conducted through eBay share some features with traditional live auctions, nevertheless differences exist as well such as the type of bidding employed during the auction. While traditional live auctions generally employ one particular type of bidding, eBay auctions for single items resemble both English and sealed bid auctions.

Bids in eBay auctions are immediately displayed on the web page devoted to the item. Therefore, anyone interested in the auction can know the current high bid as is the case in English auctions. Nevertheless, eBay auctions have a set closing time regardless of bid activity.

Auctions on eBay are also similar to first-price and second-price sealed bid auctions. There is no way for a potential bidder to know if an offered bid will be the new high bid until after submitting it; he or she may have already been outbid through the proxy bidding feature. Nevertheless, while participants in traditional sealed bid auctions only have the opportunity to submit a single bid, eBay bidders receive notice when their bids have been topped and are afforded an opportunity to submit another higher bid unless the closing time of the auction has passed. Auctions conducted on eBay which are won through the proxy bidding process bear greater similarities to second-price than to first-price sealed bid auctions since a winning bidder on eBay pays a modest increment over the second-highest bid rather than the maximum he or she is bid for the item. Nevertheless, the revenue realized in an auction won by a proxy bid should be between the amounts expected for strict second-price and first-price sealed bids. The existence of both a set ending time and a proxy bidding mechanism leads to the conclusion that the dominant strategy is for bidders to bid the maximum they are willing to pay for the item (Lucking-Reiley, 2000).

\section{Research Problem}

At this time there have been few published field studies in the auction literature that examine bidder behavior and performance. Coppinger, Smith, and Titus (1980) believe that the effects of experience with auction structures 
hold for the field as well as the laboratory as learning takes place by the process of trial-and-error. Hendrick and Paarsch (1995) criticize experiments due to lack of subject experience and incentives to bid accurately. They suggest the use of field studies to overcome these problems. The current research addresses these issues by examining revenue realized, choice of bidding mechanism, and timing of bids in the eBay market structure.

The set of auctions examined are for a collectible, the Charizard card from the Pokemon collectible card game. The items are extremely similar; only auctions for a particular card in equivalent condition were analyzed. We argue that the appropriate model to follow is that of affiliated private values since bidders have access to information regarding the values of the items by examining other current and recent auctions.

Very experienced bidders may have learned the necessary skills to allow them to set bid so that they pay less for items than less experienced bidders. In addition, their experience on eBay should allow them to more easily search and obtain information regarding the range of recent selling prices for a particular item so that they may submit bids at the lower end of the range.

H1: Very experienced bidders will pay less than very inexperienced bidders.

Proxy bidding on eBay is the dominant strategy due to the fact that earlier bids take precedence in case of ties. Vakrat and Seidmann (1999) assert that one cost to bidders of participating in auctions is that of monitoring the auction to update any bids that have been topped. They recognize proxy bidding tools as an attempt to reduce that cost to bidders. More experienced bidders may be more likely to recognize the dominance of proxy bids and the ability of the proxy bidding feature on eBay to reduce this monitoring cost and, therefore, make greater use of this tool in submitting winning bids.

H2: Very experienced bidders will win auctions with proxy bids more often than very inexperienced bidders.

Vakrat and Seidmann (1999) maintain that bidders should prefer auctions which are closing sooner to those with closing times farther in the future. More experienced bidders may find it easier to find auctions near closing times than those less experienced.

H3: Very experienced bidders will submit winning bids later in the auction process than very inexperienced bidders.

Although the preceding hypotheses follow from previous research in information systems and on auctions, there is some evidence such as that supplied by Kagel, Harstad, and Levin (1987) and Ward and Clark (2002) that experienced bidders do not always perform significantly better than inexperienced bidders. Nevertheless, Kagel, Harstad, and Levin examined bidders competing in, at most, 30 or 31 second-price sealed bid auctions. Bidders in auctions employing more complicated structures than the familiar English auctions may need more experience than that to boost performance. In addition, the field study setting allows the analysis of auctions with actual monetary incentives in place to bid well. The laboratory setting of Kagel, Harstad, and Levin's study may have contributed to the participants' level performance throughout the course of the study. Ward and Clark analyzed the experience level of all bidders; comparing the most experienced group with the least experienced group may yield significant results as well.

\section{Methods}

The current research examines single-item auctions in the collectibles area. This allows analysis of bidding behavior in many extremely similar auctions. The results of a large number of successful and active auctions of essentially identical Charizard cards were analyzed. Successful and active auctions are defined as those auctions for which there are at least two bidders and the reserve price, if any, is met. Winning bid, winning bid type, the timing of winning bids, and bidder experience level were examined to determine whether significant differences in bidder experience in online auctions have the hypothesized effects. Winning bid is the amount of the last bid. Winning bid type is coded as either proxy or English-style. The timing of bids is defined as the amount of time remaining before the 
end of the auction that the winning bid was submitted. Bidder experience level is based on the number of feedback points accrued by the winning bidder. Table 1 includes descriptive statistics for all numerical variables of interest. 83 auctions were won by bidders using the proxy bidding mechanism; 152 auctions were won by bidders using English-style bids.

Table 1

Descriptive Statistics for All Auctions

\begin{tabular}{|c|c|c|c|}
\hline Variable & Mean & $\begin{array}{c}\text { Standard } \\
\text { Deviation }\end{array}$ & $\mathbf{N}$ \\
\hline Winning Bid & $\$ 23.27$ & 6.14 & 235 \\
\hline $\begin{array}{c}\text { Winning Bid Submission } \\
\text { Time to Close of Auction }\end{array}$ & $5: 52: 46$ & $20: 36: 49$ & 235 \\
\hline Bidder Experience Level & 51.03 & 104.57 & 235 \\
\hline
\end{tabular}

As extreme differences in experience level are of interest in the current study, two groups of bidders were identified, very experienced and very inexperienced bidders. Very experienced bidders were defined as those bidders in the top quartile by experience as measured by the total number of feedback points accrued by each bidder. Very inexperienced bidders were defined as those bidders in the bottom quartile. Table 2 presents descriptive statistics for all numeric variables by each of these groups. An inspection reveals likely significant differences in the time remaining when winning bids were submitted and in bidder experience level. Winning bid amounts appear very similar between the two groups.

Table 2

Descriptive Statistics for Very Experienced and Very Inexperienced Bidders

\begin{tabular}{|c|c|c|c|c|c|c|}
\hline & \multicolumn{2}{|c|}{ Very Experienced Bidders } & \multicolumn{2}{c|}{ Very Inexperienced Bidders } \\
\hline Variable & Mean & $\begin{array}{c}\text { Standard } \\
\text { Deviation }\end{array}$ & N & Mean & $\begin{array}{c}\text { Standard } \\
\text { Deviation }\end{array}$ & N \\
\hline Winning Bid & $\$ 23.36$ & 6.80 & 59 & $\$ 23.61$ & 6.51 & 60 \\
\hline $\begin{array}{c}\text { Winning Bid } \\
\text { Submission Time To } \\
\text { Close of Auction }\end{array}$ & $3: 38: 18$ & $11: 59: 59$ & 59 & $11: 52: 24$ & $34: 32: 10$ & 60 \\
\hline $\begin{array}{c}\text { Bidder } \\
\text { Experience Level }\end{array}$ & 157.93 & 167.46 & 59 & 2.22 & 1.84 & 60 \\
\hline
\end{tabular}

An examination of the data presented in Table 3 reveals that both groups of bidders made greater use of English-style bids than of proxy bids.

Table 3

Type of Bid Submitted by Very Experienced and Very Inexperienced Bidders

\begin{tabular}{|c|c|c|}
\hline & Very Experienced Bidders & Very Inexperienced Bidders \\
\hline Proxy Bids & $15(25 \%)$ & $24(40 \%)$ \\
\hline English-Style Bids & $44(75 \%)$ & $36(60 \%)$ \\
\hline Total & $59(100 \%)$ & $60(100 \%)$ \\
\hline
\end{tabular}

\section{Results}

The hypothesis regarding the amount paid by bidders with different levels of experience was investigated with a t-test. The variables selected for testing this hypothesis were the revenue realized by the auction (i.e., the winning bid), and the experience level of the bidder. Table 4 includes the results of this analysis. There is no significant difference between the winning bids for the two groups. Very experienced bidders do not pay significantly less than very inexperienced bidders do. Hypothesis 1 is not supported. 
Table 4

T Test for Winning Bid by Bidder Experience Level

\begin{tabular}{|c|c|c|c|c|c|c|}
\hline \multicolumn{3}{|c|}{ Very Experienced Bidders } & \multicolumn{3}{|c|}{ Very Inexperienced Bidders } & \multirow[b]{2}{*}{ t stat } \\
\hline Mean & $\begin{array}{l}\text { Standard } \\
\text { Deviation }\end{array}$ & $\mathbf{N}$ & Mean & $\begin{array}{l}\text { Standard } \\
\text { Deviation }\end{array}$ & $\mathbf{N}$ & \\
\hline$\$ 23.36$ & 6.80 & (59) & $\$ 23.61$ & 6.51 & $(59)$ & $\begin{array}{c}-0.20 \\
(\mathrm{p}=0.84)\end{array}$ \\
\hline
\end{tabular}

The use of proxy and English-style bids by the different experience level groups was examined using chi-square analysis (chi-square, 2.87, $\mathrm{p}=0.09$ ). There is slight evidence of a relationship between the experience level of bidders and their use of the proxy bidding mechanism. Nevertheless, the relationship is in the opposite direction from that hypothesized. Very inexperienced bidders appear to make greater use of the proxy bidding mechanism than would be expected if the usage was uniform between the two groups. Similarly, very experienced bidders submit proxy bids less often than uniform usage would predict. Hypothesis 2 is not supported.

The timing of winning bid submissions by the different experience level of bidders was also analyzed with a $t$ test. Table 5 presents the results of this analysis. The evidence suggests that very experienced bidders do exhibit a propensity to submit bids closer to the closing time of the auction than do very inexperienced bidders. Hypothesis 3 receives weak support.

Table 5

T Test for Winning Bid Submission Time by Bidder Experience Level

\begin{tabular}{|c|c|c|c|c|c|c|}
\hline \multicolumn{3}{|c|}{ Very Experienced Bidders } & \multicolumn{3}{c|}{ Very Inexperienced Bidders } & N \\
\hline Mean & $\begin{array}{c}\text { Standard } \\
\text { Deviation }\end{array}$ & $\mathbf{N}$ & Mean & $\begin{array}{c}\text { Standard } \\
\text { Deviation }\end{array}$ & t stat \\
\hline $3: 38: 18$ & $11: 59: 59$ & $(59)$ & $11: 52: 24$ & $34: 32: 10$ & $(60)$ & -1.74 \\
$(\mathrm{p}=0.09)$
\end{tabular}

\section{Discussion}

This study examines bidder experience in online auctions and its effects on winning bids, use of proxy bidding mechanisms, and bid submission timing. Conflicting evidence from prior research involving laboratory experiments and investigations of online auction participants exists as to whether bidder experience has an effect on performance. The current research presents a field study to compare the performance of a number of bidders on eBay, the most popular online auction site for consumers. Although the very experienced bidders had participated in significantly more auctions than the very inexperienced group, a mean of 157.93 versus 2.22 , there is little evidence that their performance differed as hypothesized.

The contention that more experienced bidders would win auctions with lower bid amounts than inexperienced bidders was not supported by the analysis. The vast difference in the level of experience between the two groups makes this finding particularly interesting. The high variability found in the prices paid in different auctions, between $\$ 10.50$ and $\$ 46.00$, indicates that it should be possible to acquire the item at a relatively low price, yet very experienced auction participants do not pay any less than those with very little experience.

Much previous research in information systems and related to auctions has indicated that more experienced information systems users and more experienced bidders perform better than those less experienced. Evidence to the contrary, such as that provided by Kagel, Harstad, and Levin's (1987) study, has been attributed to the lack of information bidders have in second-price sealed bid auctions. As noted earlier, eBay auctions share several characteristics with second-price auctions, yet bidders on eBay have access to a greater amount of information regarding the interest of other auction participants. For example, the current high bid and the eBay username of all active bidders are posted. Bidders are also notified if another participant outbids them. This knowledge should mitigate the effects of the 
relative dearth of information available to participants in the traditional sealed bid auctions, yet experienced bidders still did not exhibit learning effects that would allow them to reduce the price paid.

Observed effects include the difference in the use of proxy bids and the timing of bid submissions by the two groups. Although theory suggests that very experienced bidders should be more likely to realize the conservation of effort provided by the proxy bidding mechanism, only $25 \%$ of them used proxy bids versus $40 \%$ of the very inexperienced bidders. One possible explanation is that more experienced bidders have developed that experience by voluntarily spending more time on eBay; they may enjoy spending time and effort in this manner and not see the need to monitor auctions as a cost. In addition, this group does bid in auctions closer to the set ending time than the very inexperienced group does so they may not feel the monitoring to be as burdensome. Wolfinbarger and Gilly (2001) describe two groups of online consumers, goal-oriented and experiential. Goal-oriented consumers wish to complete the transaction as quickly as possible. Experiential consumers enjoy the process of online shopping and enjoy interactivity, as is present in auctions. Perhaps the more experienced eBay bidders are representative of experiential users and, therefore, wish to participate actively near the end of the auction. Many less experienced bidders may purchase items on eBay in order to reach their goals of completing transactions and use proxy bids as a means of doing so.

\section{Contributions And Significance}

To date, there has been little published research on the effects of bidder experience on revenue and bidding strategy choices in single-item auctions. The results of this study should be applicable to other auction sites with market structures similar to eBay and have implications for bidders and auction researchers.

The most significant finding is that experienced bidders do not pay less than very inexperienced bidders, although other differences in behavior exist. That both goal-oriented and experiential consumers often participate in and win auctions on this online auction site demonstrates that eBay's market structure has sufficient characteristics to attract both types of participants.

\section{References}

1. Alavi, M. and Joachimsthaler, E. A., "Revisiting DSS Implementation Research: A Meta-Analysis of the Literature and Suggestions for Researchers", MIS Quarterly (16:1), March 1992, pp. 95-116.

2. Avery, C. and Kagel, J. H., "Second-Price Auctions with Asymmetric Payoffs: An Experimental Investigation”, Journal of Economics and Management Strategy (6:3), Fall 1997, pp. 573-603.

3. Coppinger, V. M., Smith, V. L., and Titus, J. A., "Incentives and Behavior in English, Dutch, and Sealed-Bid Auctions", Economic Inquiry (18), January 1980, pp. 1-22.

4. Dyer, D., Kagel, J.H., and Levin, D., "A Comparison of Naïve and Experienced Bidders in Common Value Offer Auctions: A Laboratory Analysis", The Economic Journal (99:394), March 1989, pp. 108-115.

5. EBay, Inc., 2002, “eBay Inc. Announces Second Quarter 2002 Financial Results”, Retrieved July 29, 2002 from the World Wide Web: http://www.shareholder.com/ebay/releases-earnings.cfm.

6. Garvin, S. and Kagel, J. H., "Learning in common value auctions: Some initial observations", Journal of Economic Behavior and Organization (25:3), 1994, pp. 351-372.

7. Hendricks, K. and Paarsch, H. J., "A Survey of Recent Empirical Work Concerning Auctions," Canadian Journal of Economics (28:2), May 1995, pp. 403-426.

8. Kagel, J., Harstad, R., Levin, D., "Information Impact and Allocation Rules in Auctions with Affiliated Private Values: A Laboratory Study", Econometrica (55:6), November 1987, pp. 1275-1304.

9. Kagel, J. H. and Levin, D., "The Winner's Curse and Public Information in Common Value Auctions", The American Economic Review (76:5), December 1986, pp. 894-920.

10. Kagel, J. H., Levin, D., Battalio, R., and Meyer, D. J., "First-Price Common Value Auctions: Bidder Behavior and the 'Winner's Curse'", Economic Inquiry (27:2), April 1989, pp. 241-258.

11. Levin, D. Kagel, J. H., and Richard, J., "Revenue Effects and Information Processing in English Common Value Auctions", The American Economic Review (86:3), June 1996, pp. 442-460.

12. List, J. A. and Shogren, J. F., "Price Information and Bidding Behavior in Repeated Second-Price Auctions", American Journal of Agricultural Economics (81:4), November 1999, 942-949. 
13. Lucking-Reiley, D., "Auctions on the Internet: What's Being Auctioned, and How?" The Journal of Industrial Economics (48:3), September 2000, pp. 227-252.

14. Milgrom, P. and Weber, R., "A Theory of Auctions and Competitive Bidding", Econometrica (50:5), September 1982, pp. 1089-1122.

15. Pavlou, P. A. and Ba, S., "Does Online Reputation Matter? An Empirical Investigation of Reputation and Trust in Online Auction Markets", Proceedings of the 2000 Americas Conference on Information Systems, August 10-13, 2000, Long Beach, California, U.S.A., pp. 948-950.

16. Vakrat, Y. and Seidmann, A., "Implications of the Bidders' Arrival Process on the Design of Online Auctions", Proceedings of the 33rd Annual Hawaii International Conference on System Sciences, Maui, Hawaii, January 4-7 2000.

17. Vickrey, W., "Counterspeculation, Auctions, and Competitive Sealed Tenders", Journal of Finance (16:1), May 1961, pp. 8-37.

18. Wolfinbarger, M. and Gilly, M. C., "Shopping Online for Freedom, Control, and Fun", California Management Review (43:2), Winter 2001, pp. 34-55.

19. Ward, S. G. and Clark, J. M., "Bidding Behavior in On-line Auctions: An Examination of the eBay Pokemon Card Market", International Journal of Electronic Commerce (6:4), Summer 2002, pp. 139-155.

Notes 